\title{
Comparative Study of White Layer Characteristics for Static and Rotating Workpiece during Electric Discharge Machining
}

\author{
SHAHID MEHMOOD*, MASOOD SHAH*, BAKHT BAHADUR RANA**, NAZEER AHMED ANJUM*, \\ AND AMIR SULTAN*** \\ RECEIVED ON 07.04.2016 ACCEPTED ON 16.08.2016 \\ ABSTRACT
}

\begin{abstract}
EDMed (Electric Discharge Machined) surfaces are unique in their appearance and metallurgical characteristics, which depend on different parameter such as electric parameters, flushing method, and dielectric type. Conventionally, in static workpiece method the EDM (Electric Discharge Machining) is performed by submerging both of the tool and workpiece in dielectric liquid and side flushing is provided by impinging pressurized dielectric liquid into the gap. Another flushing method has been investigated in this study, in which, instead of side flushing the rotation motion is provided to the workpiece. Surface characteristics for both flushing methods are determined and compared in this study. The investigated surface characteristics are: surface roughness, crater size, surface morphology, white layer thickness and composition. These investigations are performed using optical and SEM (Scanning Electron Microscope). Statistical confidence limits are determined for scattered data of surface roughness. It is found that the white layer thickness and surface roughness are directly proportional to discharge current for both flushing methods. The comparison has shown that the side flushing of statics workpiece gives thicker white layer and lower surface finish as compared to the flushing caused by the rotation of workpiece.
\end{abstract}

Key Words: $\quad$ Electric Discharge Machining, Aluminum Alloy, Workpiece Rotation, White Layer.

\section{INTRODUCTION}

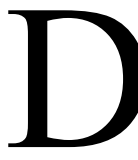
uring EDM, thermal energy generated by electric sparks is used to melt the material from surface of workpiece. A portion of molten material is splashed away due to sudden drop in the pressure after the discharge tool place [1]. The dielectric liquid removes these debris away from the gap. Dielectric liquid also preserve the fluid temperature much below the flash point [2] and cools down the workpiece and tool material after each discharge. It is believed by many researchers [3-5] that only a small portion of the molten material is swept whereas residue material resolidified on the surface forming a so-called layer having characteristics

Corresponding Author: (E-Mail: shahid.mehmood@uettaxila.edu.pk)

* Department of Mechanical Engineering, University of Engineering \& Technology, Taxila.

** Glass \& Ceramics Research Centre, PCSIR, Laboratories Complex, Ferozepur Road, Lahore.

*** Department of Mechatronics Engineering, University of Engineering \& Technology, Taxila.

Mehran University Research Journal of Engineering \& Technology, Volume 36, No. 4, October, 2017 [p-ISSN: 0254-7821, e-ISSN: 2413-7219] 
different to base material. This white layer has different thickness and appearance depending on pulse current, duty cycle, material type of workpiece and dielectric liquid [6].

Selection of proper flushing method is important to achieve desired characteristics of the white layer. There are several flushing methods discussed in the literature such as normal flow, reversed flow, jet flushing and immersed flushing $[7,8]$. For thin cuts or machining of thin foils, simple dipping of workpiece and tool in a dielectric tank is suitable. If tool electrode penetrate into the workpiece, the dielectric liquid thrown from outside even under pressure could not remove the suspended particles from the gap effectively. Therefore other methods like injection flushing is suitable in such cases [7]. Other sources for the improvement of flushing conditions may encompass relative movement between workpiece and tool electrode [9] such as orbital motion of the tool electrode[10] and Vibration assisted EDM $[8,11]$. In case of inadequate flushing, the machining conditions become unstable, due to which, arcing occurs at the positions of concentrated debris [10-12]. Consequently irregular and high tool wear occurs [13] affecting surface finish and accuracy of the workpiece [14].
In present study, EDMed surfaces of aluminum alloy 2024 T6 by two different flushing methods are compared. The evaluated flushing methods are (i) side flushing to the static workpiece and (ii) flushing by rotating the workpiece. The generated surfaces by the above mentioned methods are compared by surface characteristics i.e. Surface morphology, crater diameter, morphological observations, white layer thickness, and chemical composition.

\section{EXPERIMENTAL SETUP}

The Chemical composition of the Al $2024 \mathrm{~T} 6$ was obtained by optical emission spectrometer under ASTM E 1507 standard, and is given in Table 1. The mechanical properties of this material were obtained by hardness and tensile tests. Tensile test specimens were prepared according to ASTM-E 8M-04. Three tests were performed and their average value were taken. The average values of the material properties provided in Table 2 .

Experiments are performed by using NEUAR die-sinking EDM at room temperature. Industrial grad pure Copper is used as tool electrode and machining is performed submerged in kerosene oil. The physical properties of the copper material are shown in Table 3.

TABLE 1. CHEMICAL COMPOSITION OF ALUMINUM ALLOY (2024 T6)

\begin{tabular}{|c|c|c|c|c|c|c|c|c|}
\hline Element & $\mathrm{Si}$ & $\mathrm{Fe}$ & $\mathrm{Cu}$ & $\mathrm{Mn}$ & $\mathrm{Mg}$ & $\mathrm{Zn}$ & $\mathrm{Ni}$ & $\mathrm{Cr}$ \\
\hline$\% W t$. & 0.162 & 0.380 & 4.18 & 0.710 & 1.37 & 0.026 & 0.0039 & 0.065 \\
\hline Element & $\mathrm{Pb}$ & $\mathrm{Sn}$ & $\mathrm{Ti}$ & $\mathrm{Ca}$ & $\mathrm{P}$ & $\mathrm{Sr}$ & $\mathrm{V}$ & $\mathrm{Al}$ \\
\hline$\% W t$. & 0.0114 & 0.001 & 0.0114 & 0.0002 & 0.001 & 0.0001 & 0.0059 & 93.08 \\
\hline
\end{tabular}

TABLE 2.PHYSICAL AND MECHANICAL PROPERTIES OF ALUMINUM ALLOY (2024 T6)

\begin{tabular}{|c|c|c|c|c|c|c|}
\hline $\begin{array}{c}\text { Density } \\
(\mathrm{g} / \mathrm{cc})\end{array}$ & $\begin{array}{c}\text { Hardness } \\
(\mathrm{HRB})\end{array}$ & $\begin{array}{c}\text { Yield Strength } \\
(\mathrm{MPa})\end{array}$ & $\begin{array}{c}\text { Ult. Tensile Strength } \\
(\mathrm{MPa})\end{array}$ & $\begin{array}{c}\text { Mod of Elasticity } \\
(\mathrm{GPa})\end{array}$ & $\begin{array}{c}\text { Elongation } \\
(\%)\end{array}$ & $\begin{array}{c}\text { Liquidus/Solidus } \\
\text { Temperature } \\
(\mathrm{oC})\end{array}$ \\
\hline 2.78 & 78 & 520 & 600 & 72.4 & 11 & $638 / 502$ \\
\hline
\end{tabular}

TABLE 3: PHYSICAL PROPERTIES OF COPPER ELECTRODE[15]

\begin{tabular}{|c|c|c|c|c|c|}
\hline $\begin{array}{c}\text { Specific Heat } \\
(\mathrm{J} / \mathrm{kg} \cdot \mathrm{K})\end{array}$ & $\begin{array}{c}\text { Ther. Conductivity } \\
(\mathrm{W} / \mathrm{m} \cdot \mathrm{K})\end{array}$ & $\begin{array}{c}\text { Specific Gravity at } 20^{\circ} \mathrm{C} \\
(\mathrm{g} / \mathrm{cm} 3)\end{array}$ & $\begin{array}{c}\mathrm{CTE} \\
\left(\times 10-6\left(1 /{ }^{\circ} \mathrm{C}\right)\right)\end{array}$ & $\begin{array}{c}\text { Boiling Temperature } \\
\left({ }^{\circ} \mathrm{C}\right)\end{array}$ & $\begin{array}{c}\text { Melting Point } \\
\left({ }^{\circ} \mathrm{C}\right)\end{array}$ \\
\hline 385 & 380.7 & 8.9 & 17 & 2595 & 1083 \\
\hline
\end{tabular}

Mehran University Research Journal of Engineering \& Technology, Volume 36, No. 4, October, 2017 [p-ISSN: 0254-7821, e-ISSN: 2413-7219] 
A cylindrical shaped workpiece $\Phi 20 \times 22 \mathrm{~mm}$ is used for machining with side flushing $\left(0.9 \mathrm{Kg} / \mathrm{cm}^{2}\right)$ with a copper electrode of $22 \mathrm{~mm}$, Fig. 1(a) and prepared specimen at five different discharge current values are shown in Fig. 1(b).

The effect of workpiece rotation is investigated without side flushing, where, dog-bone shaped specimens of aluminum alloy $2024 \mathrm{~T} 6$ are machined from the center by rotating themabout their longitudinal axis.A special purpose fixture is designed and fabricated that holds the workpiece between its spindles. Constant rotation speed $(85 \mathrm{rpm})$ is provided by a DC motor to the workpiece with the help of power supply. Fig.2(a). Cylindrical copper tool electrode of $\Phi 10 \times 10 \mathrm{~mm}$ along with machined specimen is shown in Fig. 2(b). For both methods DOM (Depth of Machining) is fixed. Peak current values are varied only while all other parameters are kept constant and are presented in Table 4.
SEM (Scanning Electron Microscope) is used for surface morphology, white layer thickness and EDS (Energy Dispersive Spectrographs). For measurement of white layer thickness, the specimen are sliced from center. After mirror like polishing and etching with diluted HF solution, the specimen is examined by digital metallurgical microscope and about 3-5 measurements are taken for each specimen and their average value is considered. Digital metallurgical microscope is also used for the investigation of crater diameter from the cross-section of electric discharge machined surface. The average value of 10-15 craters is taken from the cross-sectional image of each specimen.

The surface roughness has been determined from the profile of the cross-sectional images obtained by optical microscope at the magnification of 200x, as shown in Fig. 3(a). The surface profile of the image is then digitized. A DIP (Digital Image Processing) method used in current

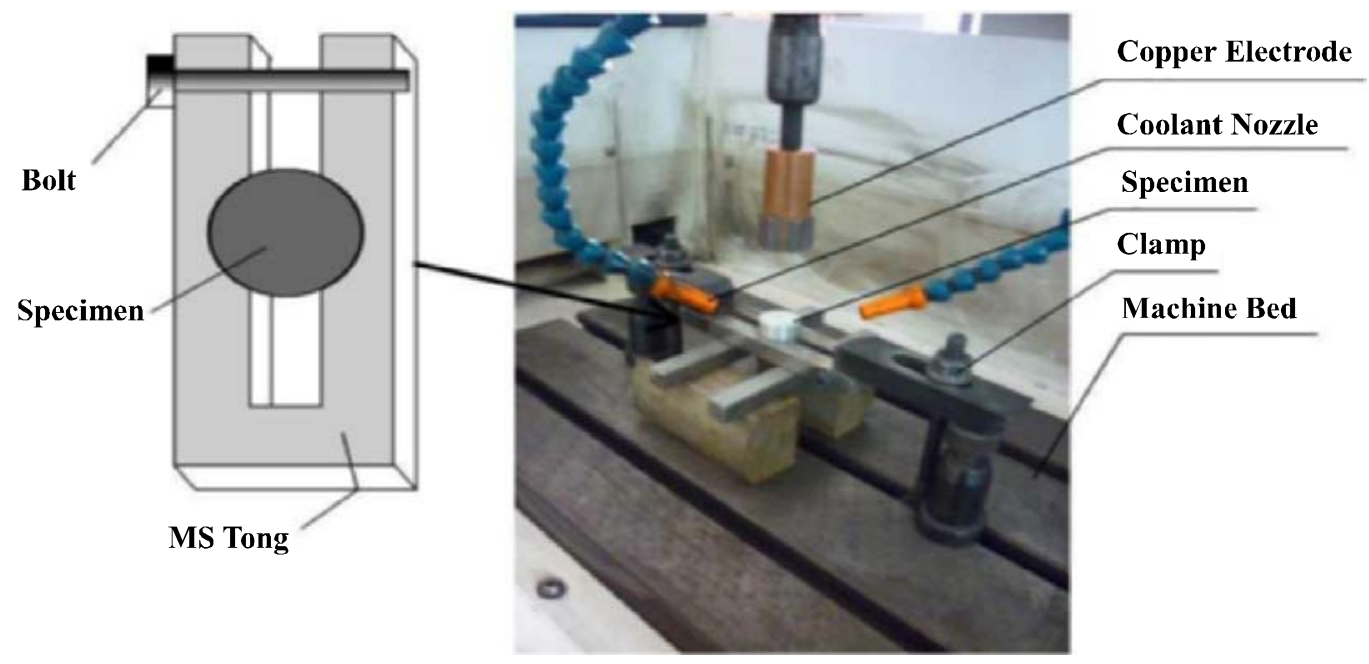

(a) STATIC WORKPIECE

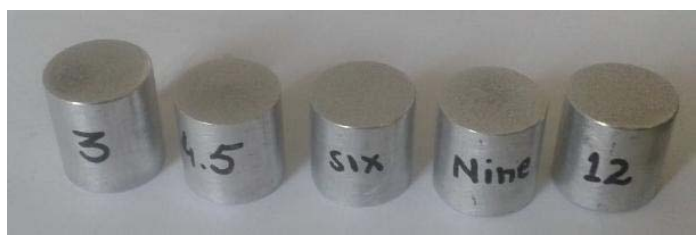

(b) SPECIMENS PREPARED

FIG. 1. EXPERIMENTAL SETUP

Mehran University Research Journal of Engineering \& Technology, Volume 36, No. 4, October, 2017 [p-ISSN: 0254-7821, e-ISSN: 2413-7219] 
study involves a software "Enguage Digitisor" ${ }^{\mathrm{TM}}$ " to digitize the surface profile. The surface profile is highlighted and its parameters are drawn. Average surface roughness $\left(R_{a}\right)$ is determined from the profile of each image by Equation (1). Five images from different locations of each workpiece are analyzed. Lower and upper bounds at the confidence interval of 95 and $50 \%$ are obtained by using T-distribution.

$\mathrm{R}_{\mathrm{a}}=\frac{1}{\mathrm{n}} \sum_{\mathrm{i}=1}^{\mathrm{n}}\left|\mathrm{y}_{\mathrm{i}}-\mathrm{m}\right|$
Where $y_{i}$ is height of crest/trough from reference line, $\mathrm{m}$ is height of mean line from reference line, and $\mathrm{n}$ is total number of data points

\section{RESULTS AND DISCUSSION}

SEM image of the white layer formed at 3 ampere for each method is shown in Fig. 4. The results of the AWLT (Average White Layer Thickness) of both methods at all discharge currents are plotted in Fig. 5. From 3-4.5 ampere no change in the AWLT is observed for both cases.

TABLE 4. CONSTANT PROCESS PARAMETER USED FOR BOTH EDM METHODS

\begin{tabular}{|c|c|c|c|c|c|c|c|}
\hline Pulse-ON Time & Pulse-OFF Time & Voltage & Gap Distance & DOM & Polarity & Dielectric Liquid & Electrode Material \\
\hline $60 \mu \mathrm{m}$ & $4 \mu \mathrm{m}$ & $110 \mathrm{~V}$ & $5 \mu \mathrm{m}$ & $1 \mathrm{~mm}$ & Positive & Kerosene Oil & Pure Copper \\
\hline
\end{tabular}

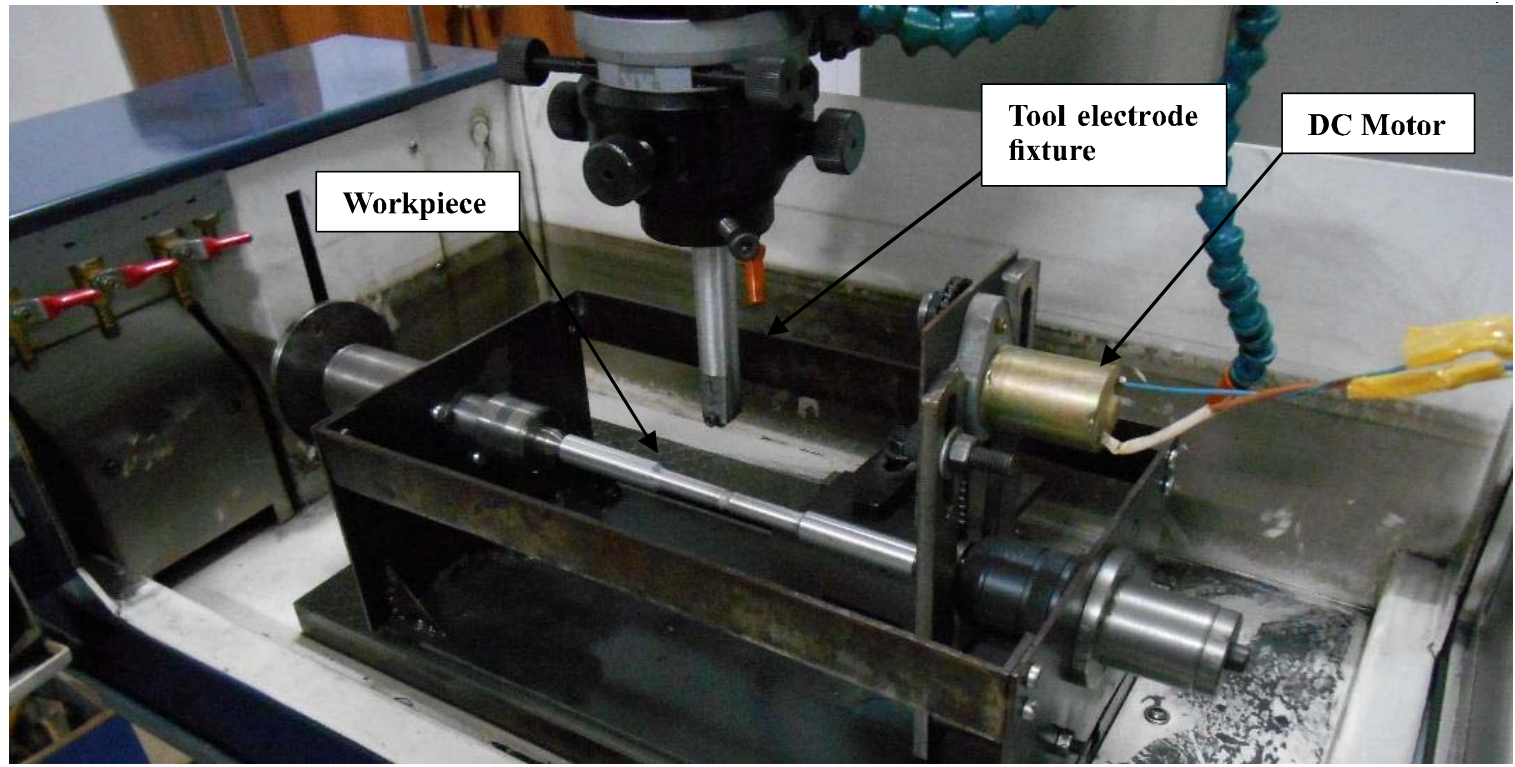

FIG. 2(a). WORKPIECE ROTATION SETUP ON EDM BED

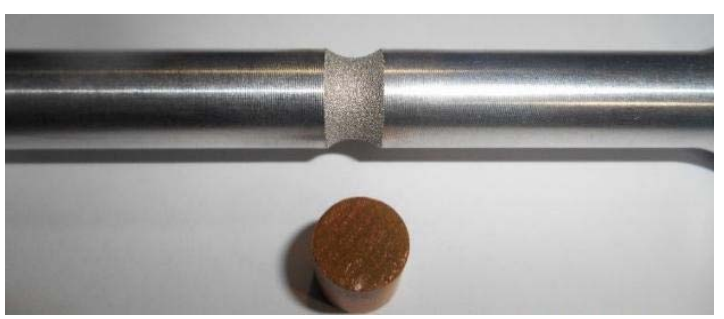

FIG. 2(b). COPPER ELECTRODE WITH PREPARED SPECIMEN

Mehran University Research Journal of Engineering \& Technology, Volume 36, No. 4, October, 2017 [p-ISSN: 0254-7821, e-ISSN: 2413-7219] 


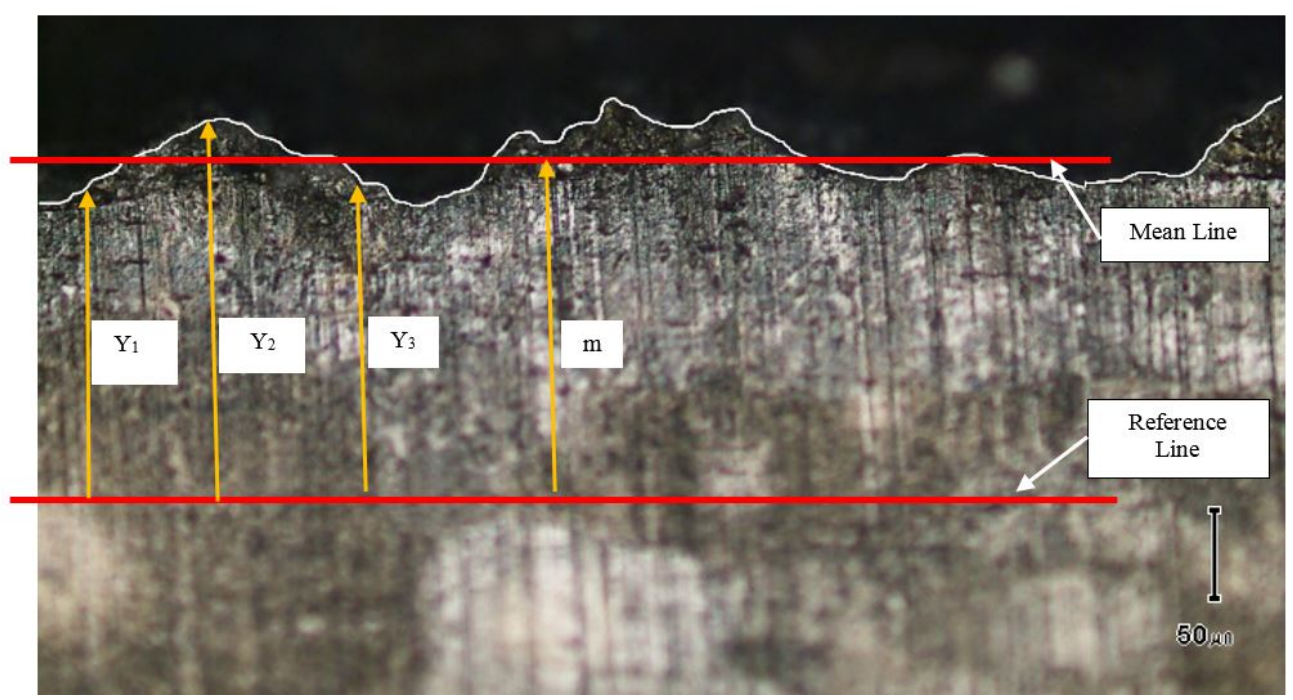

FIG. 3. ILLUSTRATION OF SURFACE PROFILE (a) ACTUAL IMAGE (b) GENERAL PROFILE OF EDMED SURFACE

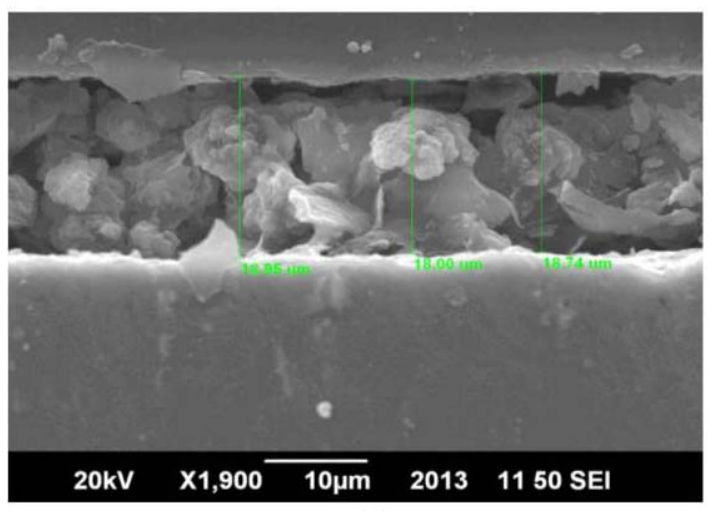

(a)

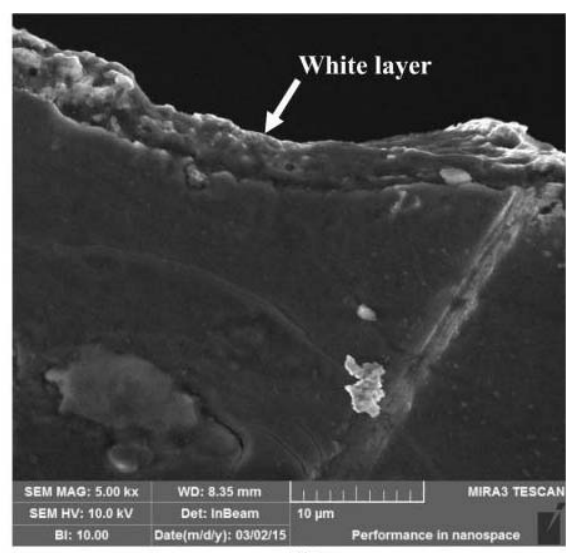

(b)

FIG. 4. SEM IMAGE OF THE WHITE LAYER FORMED AT 3 AMPERE (a) STATIC WORKPIECE (b) ROTATING WORKPIECE

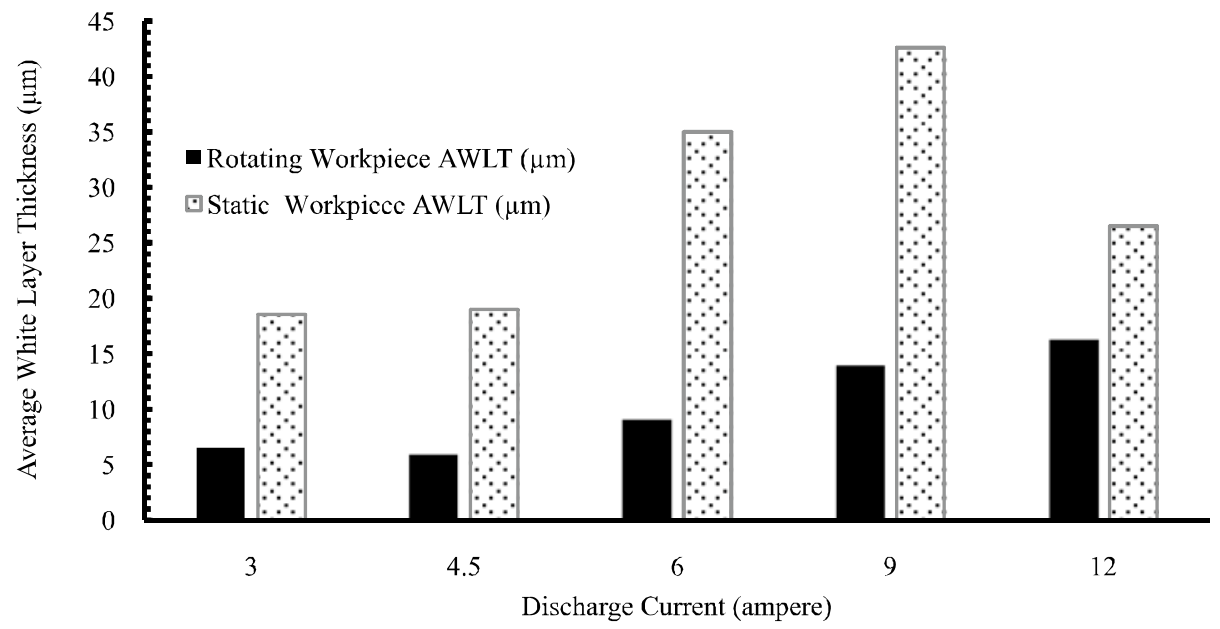

FIG. 5. COMPARISON OF THE AWLT FOR ROTATING AND STATIC WORKPIECE

Mehran University Research Journal of Engineering \& Technology, Volume 36, No. 4, October, 2017 [p-ISSN: 0254-7821, e-ISSN: 2413-7219] 
Workpiece rotation giveslower AWLT from 3-9 ampere but this difference is reduced at 12 ampere. As Arooj et. al. [16] explained that the white layer formed at 12 ampere was severely cracked which might have removed the excessive amount of the surface layer at this high discharge current. The comparison of the white layer thickness is clearly depicting the improved flushing effect in case of workpiece rotation as compared to the side flushing of the static workpiece. The reason for this improved flushing for rotating workpiece is due to improved circulating of the dielectric fluid and the expulsion of the debris by the centrifugal force.

The surface morphology for both methods is shown for 3, 6 and 9 amperes in Fig. 6. Cracks do not appear at 3 ampere but the appendages of the molten material are prominent for both method but these are smaller for the static workpiece. It is clearly noticed that as the discharge current level is increased to 6 ampere the surface of the static workpiece is cracked and became rough as compared to the rotating workpiece. For the discharge current of 12 ampere the surface for rotating workpiece is also showing some cracks but the density of cracks is much lower than that of static workpiece. These observations reveal that side flushing for static workpiece at 3 ampere discharge current level is sufficient. With the increase of discharge current level the quantity of molten material is increased that was not removed properly in case of static workpiece.

In contradiction to the conventional machining processes like turning and milling where tool marks appears on the machined surface, the EDMed surface has hemispherical cavities known as "craters". Optical cross-sectional image of the EDMed is presented in Fig. 7, which is clearly showing these craters. For precise results the diameter of all craters is measured from eachimage and average of three images at each discharge current is used.
Results for average crater diameter are shown in Fig. 8 which make it clear that the crater size is proportional to the discharge current value for both cases. The craters behavior is representing that the intensity and distribution of the sparks are of chaotic nature, due to which, average of crater diameter is considered. The comparison between the crater diameter for rotating and static workpiece shows that the crater size for rotating workpiece is comparatively higher. This result may reveal that the flushing efficiency due to workpiece rotation is superior to the conventional side flushing of static workpiece.

The outcome of the EDS analysis reveals the contamination of white layer by carbon and copper contents. The disintegration of kerosene oil takes place while machining at high temperature and some carbon elements are mixed in the molten material on workpiece surface. The copper contents are transferred from tool electrode as the surface of the tool electrode also melts and erodes during machining. Fig. 9 presents the contents of the contaminated carbon in the white layer formed at 6 , 9 and 12 amperes for both methods. It is observed that the contamination of white layer by the carbon (formed by the decomposition of kerosene oil during EDM) remain same for all investigated peak current values in case of static workpiece with side flushing. Whereas for rotating workpiece the amount of carbon contents is higher than the static workpiece at the lower values of the peak currents and is inversely proportional to the peak current values. The amount of carbon contents for rotating workpiece decreases than that of the static workpiece with side flushing at 12 ampere. The increased amount of carbon contents in aluminum alloys is deleterious for surface integrity. Carbon may react with other intermetallic inclusions to form its carbides but mostly it reacts with aluminum to form $\mathrm{Al}_{4} \mathrm{C}_{3}$, which is soluble in water and its vapors. The dissolution of $\mathrm{Al}_{4} \mathrm{C}_{3}$ may lead to surface pitting. 

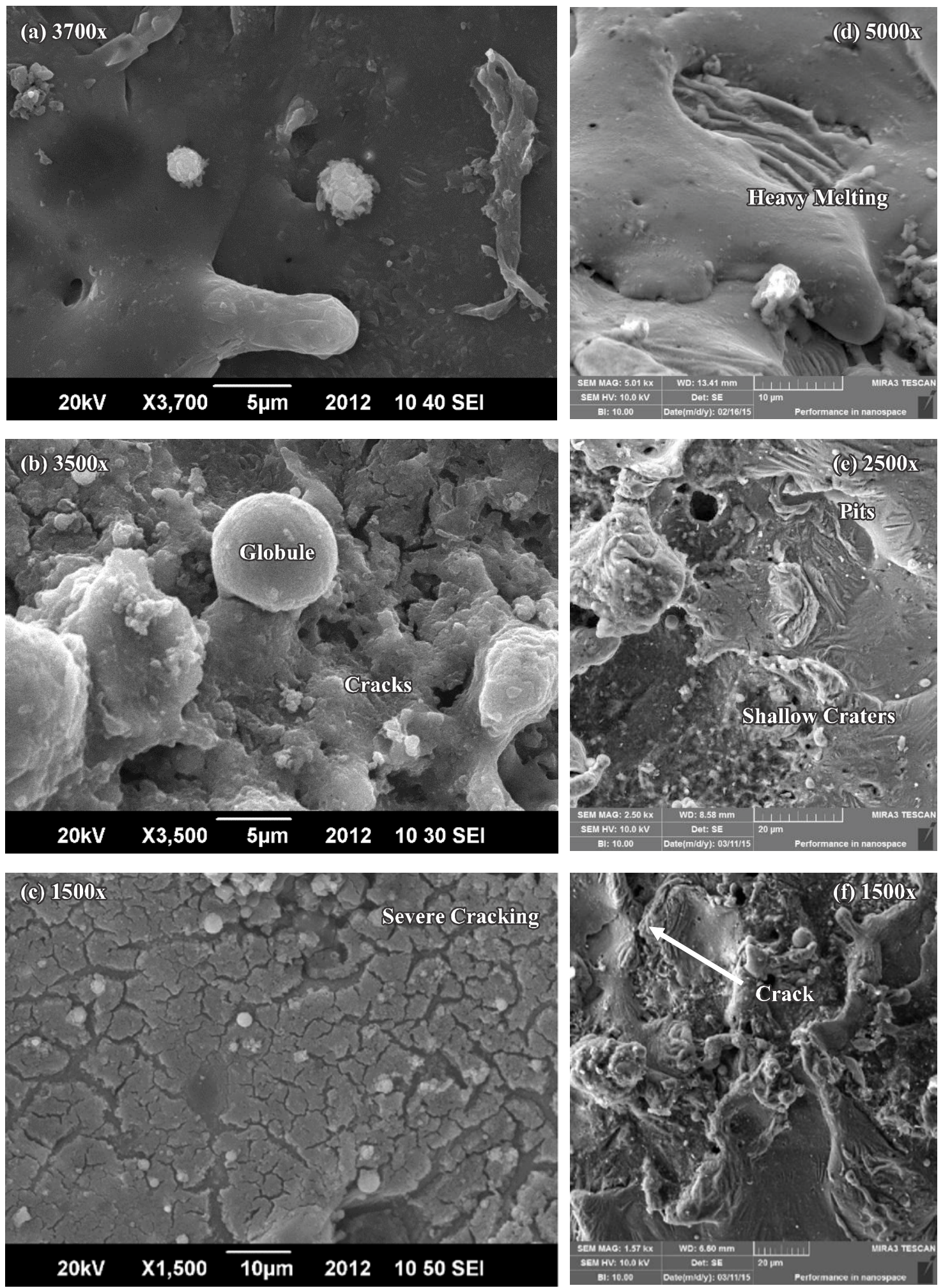

FIG. 6. COMPARISON OF SURFACE MORPHOLOGY FOR 3, 6 AND 9 AMPERES, (A-C) STATIC WORKPIECE, (D-F) ROTATING WORKPIECE

Mehran University Research Journal of Engineering \& Technology, Volume 36, No. 4, October, 2017 [p-ISSN: 0254-7821, e-ISSN: 2413-7219] 


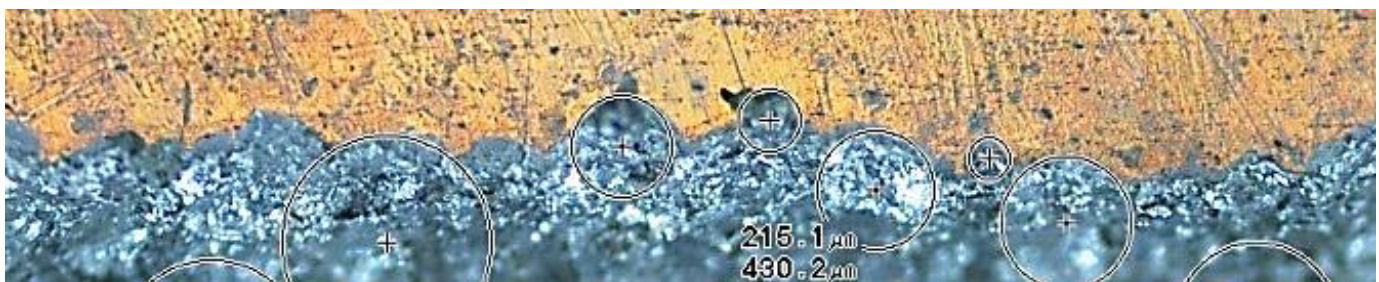

FIG. 7. MEASUREMENT OF AVERAGE CRATER SIZE BY DIGITAL METALLURGICAL MICROSCOPE FROM CROSS-SECTION

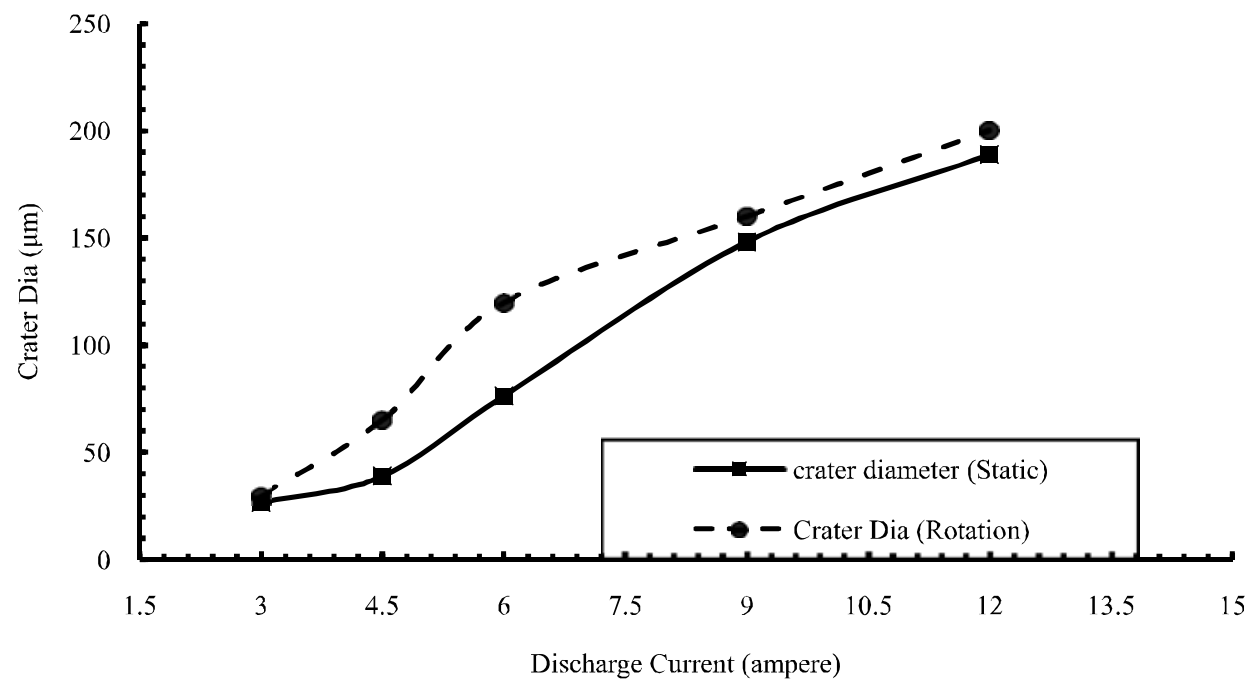

FIG. 8. COMPARISON OF THE CRATER DIAMETERS OF THE STATIC AND ROTATING WORKPIECE

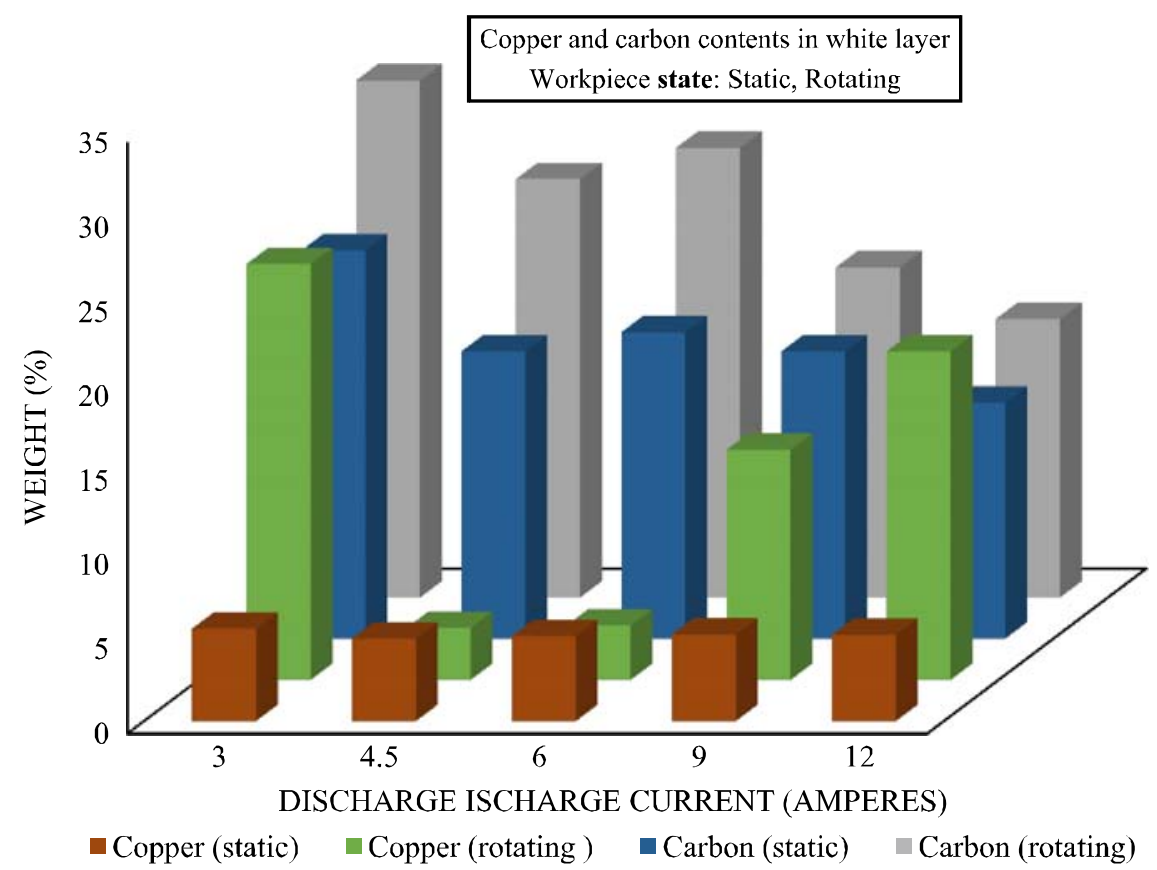

FIG. 9. CONTAMINATION OF WHITE LAYER BY CARBON FOR STATIC AND ROTATING WORKPIECE

Mehran University Research Journal of Engineering \& Technology, Volume 36, No. 4, October, 2017 [p-ISSN: 0254-7821, e-ISSN: 2413-7219] 
A percentage of $4-6 \%$ copper is usually maintained to achieve the maximum strength properties of aluminum alloy. Results are showing that the transfer of copper contents from tool electrode to the workpiece is negligible for the static workpiece at all investigated discharge current levels. But for rotating workpiece the amount of copper contents is proportionally increasing with discharge current level from 6-12 ampere discharge current [17]. At 3 ampere discharge current, an increase in carbon and copper contents is observed. The reason for increase in copper contents for rotating specimen is associated with the short gap distance between electrode and workpiece for low discharge current. When compared with static workpiece, no such increase in copper contents in the white layer occurred. Workpiece rotation at 3 ampere (small current) is the reason of white layer contamination by electrode material. Increase in carbon contents is observed which is in agreement with some previous studies for EDM in kerosene oil, and argued that these carbon contents are transferred from kerosene oil into machined surface $[2,18]$. It is seen that contamination of white layer with carbon material is occurred for static and rotating workpieces. The amount of carbon content in machined surface is more for rotating workpiece as compared to static workpiece. Overall it could be established that the contamination of the white layer by carbon and copper contents is lower for static workpiece as compared to the rotating workpiece.

Surface morphology revealed that EDMed surface is composed of hollow globules andshallow craters. The tip of roughness profile meter penetrate into the surface resulting error in readings and a line mark was generated. Therefore, accurate surface roughness has been found by this non-contact methods. The mean value of the surface roughness of rotating workpiece is lower than the static workpiece at all discharge current levels but it can be only absolutely differentiated at the discharge current of 6 ampere. In Table 5, surface roughness values at all discharge current levels are presented for static and rotating workpiece respectively, and error bars are representing using standard deviation. The mean values of the surface roughness for static and rotating workpieces are presented in Fig. 10. Due to scatter in the roughness values at the investigated discharge currents for both methods, Confidence intervals of 95 and $50 \%$ are determined by using T-distribution and are shown in Figs. 11-12 for static and rotating workpiece respectively. Trend curves along with their $\mathrm{R}^{2}$ values are plotted for each individual method which will help to understand the roughness behavior with respect to discharge current. The value of coefficient of determination $\left(\mathrm{R}^{2}\right)$ of each curve is also presented in the graph.

TABLE 5. ARITHMETIC MEAN SURFACE ROUGHNESS” RA” $(\mu \mathrm{m})$ FOR STATIC AND ROTATING WORKPIECE

\begin{tabular}{|c|c|c|c|c|c|c|c|c|}
\hline \multicolumn{1}{|c|}{ Trial\# } & \multicolumn{4}{|c|}{ Rotating Workpiece } & \multicolumn{4}{c|}{ Static Workpiece } \\
\hline Discharge Current (ampere) & $3 \mathrm{~A}$ & $6 \mathrm{~A}$ & $9 \mathrm{~A}$ & $12 \mathrm{~A}$ & $3 \mathrm{~A}$ & $6 \mathrm{~A}$ & $9 \mathrm{~A}$ & $12 \mathrm{~A}$ \\
\hline 1 & 4.56 & 8.61 & 12.27 & 10.68 & 5.48 & 9.44 & 12.27 & 12.15 \\
\hline 2 & 6.15 & 7.21 & 10.18 & 12.52 & 6.47 & 11.82 & 10.18 & 12.73 \\
\hline 3 & 7.38 & 8.28 & 10.02 & 9.93 & 6.15 & 11.45 & 16.14 & 13.02 \\
\hline 4 & 4.82 & 8.88 & 9.72 & 10.23 & 7.38 & 12.78 & 9.72 & 12.94 \\
\hline 5 & 4.62 & 8.7 & 10.62 & 14.03 & 7.47 & 10.71 & 10.62 & 11.65 \\
\hline Average "Ra" ( $\mu \mathrm{m})$ & 5.51 & 8.34 & 10.56 & 11.47 & 6.59 & 11.24 & 11.78 & 12.49 \\
\hline Standard Deviation & 1.23 & 0.67 & 1.01 & 1.73 & 0.84 & 1.25 & 2.62 & 0.58 \\
\hline
\end{tabular}

Mehran University Research Journal of Engineering \& Technology, Volume 36, No. 4, October, 2017 [p-ISSN: 0254-7821, e-ISSN: 2413-7219] 
It could be observed that surface roughness is increasing with increasing discharge current which is in agreement with previous investigations $[1,19,20]$. This is because as the intensity of spark become stronger with increasing discharge current. Intense electric sparks have higher material removal rate and consequently larger craters generate [21]. According to surface morphological observations in current study, it is seen that surface irregularities increase when performing EDM at relatively high discharge currents regardless flushing method. The comparison between surface rough-nesses obtainedby both investigated flushing methods revealed that workpiece rotation results superior surface finish even without any external flushing.

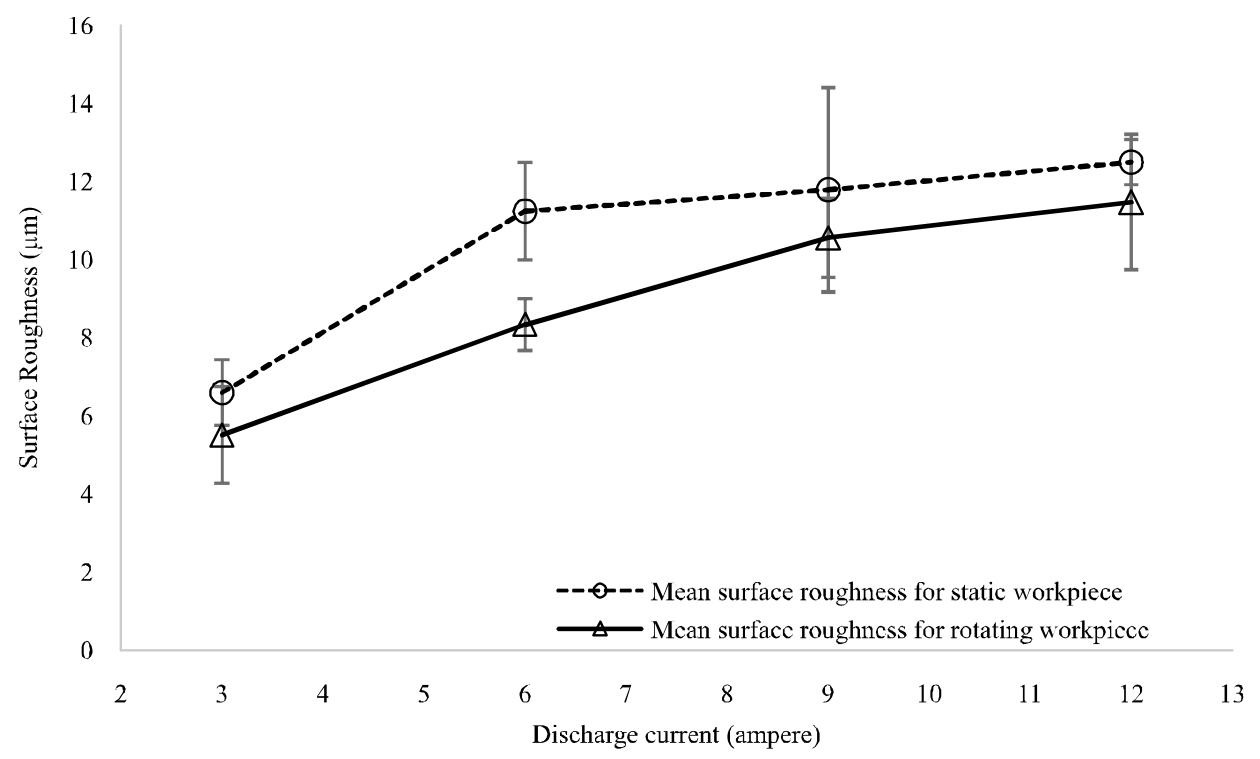

FIG. 10. COMPARISON OF SURFACE ROUGHNESS FOR STATIC AND ROTATING WORKPIECE

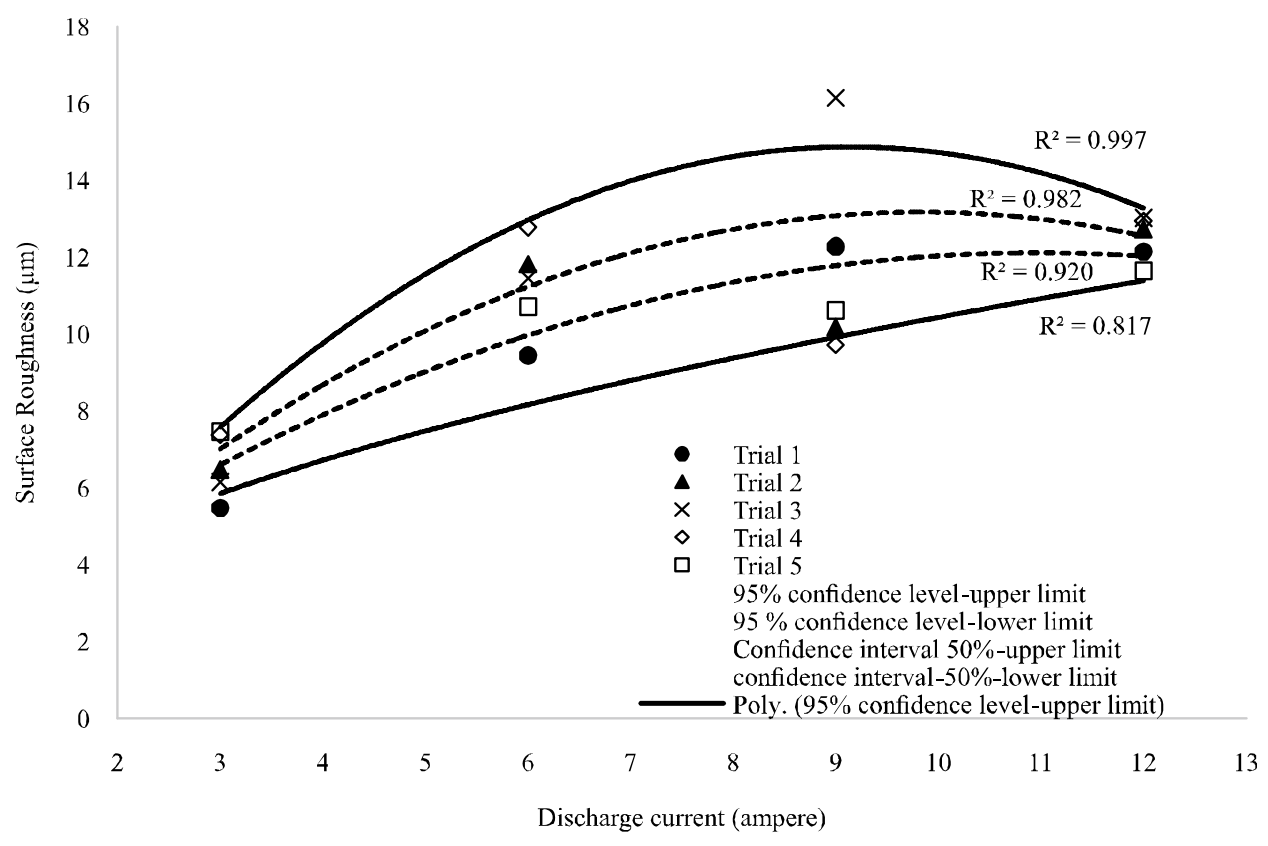

FIG. 11. SHOWING 95 AND 50\% CONFIDENCE INTERVALS OF SURFACE ROUGHNESS OF STATIC WORKPIECE

Mehran University Research Journal of Engineering \& Technology, Volume 36, No. 4, October, 2017 [p-ISSN: 0254-7821, e-ISSN: 2413-7219] 


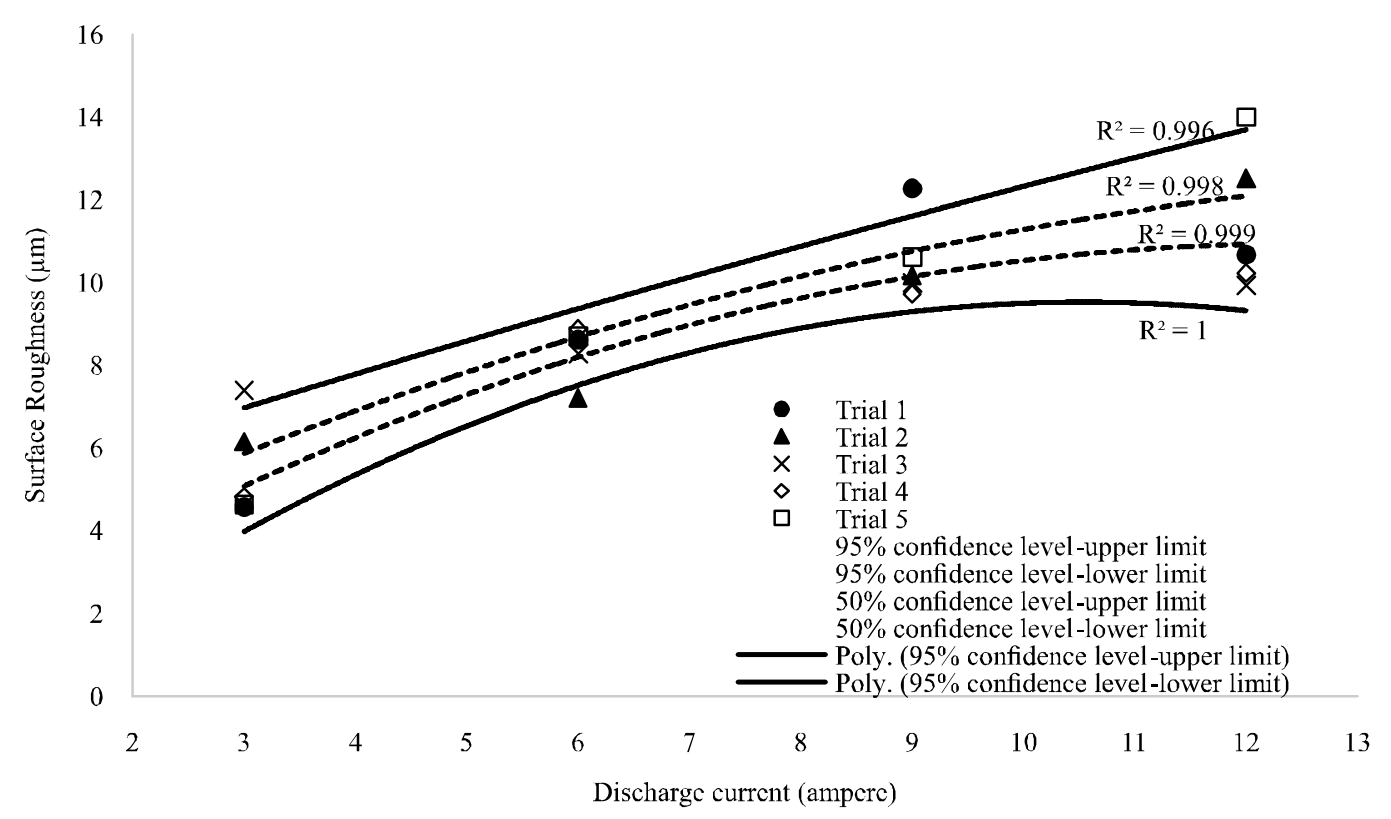

FIG. 12. SHOWING 95 AND 50\% CONFIDENCE INTERVALS OF SURFACE ROUGHNESS OF ROTATING WORKPIECE

\section{CONCLUSION}

Main objective of current investigation is to study the effect of discharge current on the surface integrity of aluminum alloy $2024 \mathrm{~T} 6$ for static and rotating workpiece. The integrity of EDMed surface is evaluated by morphological examinations, white layer thickness, crater size, roughness and chemical composition of the white layer. The workpiece rotation during EDM, with no other flushing, generates thinner white layer as compared to that of static workpiece provided with side flushing. The decrease in the thickness of white layer in case of rotating workpiece is attributed to the enhanced flushing of the debris from inter-electrode gap.The surface morphology reveals that workpiece rotation is causing less surface defects like micro-cracks, pits, globules and appendages of the resolidified molten material when compared for different discharge current levels for static and rotating workpieces during EDM.The diameter of the crater is found proportional to the discharge current for static as well as for rotating workpiece. But the size of crater diameter for the rotating workpiece is slightly larger than the static work piece with side flushing. White layer formed on rotating workpiece is not contaminated by copper contents. Due to cracking of the kerosene oil at very high temperature, the carbon contents are produced and are absorbed by the white layer for both methods. For static workpiece, the amount of carbon contents is more at 9 ampere but for rotating workpiece, this value is continuously decreasing with the increase of discharge current.The mean values of surface roughness at the investigated discharge current values for rotating workpiece is found lower than that of static workpiece. There is scatter in the data that shows heterogeneous and complex probabilisticspark phenomenon during electric discharge machining. 95 and 50\% confidence intervals for the surface roughness at all investigated discharge current values are established which will help to understand surface roughness behavior with respect to discharge current for both static and rotating workpiece during EDM.

\section{ACKNOWLEDGEMENT}

This research work was funded and supported by University of Engineering \& Technology, Taxila, Pakistan, under research grant no. FME-ME-250, which is highly acknowledged. Special thanks to Technopak Engineering Private Limited, for his technical and logistic support during sample preparation and Institute of Space Technology for scanning electron microscopy.

Mehran University Research Journal of Engineering \& Technology, Volume 36, No. 4, October, 2017 [p-ISSN: 0254-7821, e-ISSN: 2413-7219] 


\section{REFERENCE}

[1] Torres, A., Puertas, I., and Luis, C. J., "Modelling of Surface Finish, Electrode Wear and Material Removal Rate in Electrical Discharge Machining of Hard-toMachine Alloys", Precision Engineering, Volume 40, pp. 33-45, 2015.

[2] Zhang, Y., Liu, Y., Shen, Y., Ji, R., Li, Z., and Zheng, C., "Investigation on the Influence of the Dielectrics on the Material Removal Characteristics of EDM", Journal of Materials Processing Technology, Volume 214, No. 5,pp. 1052-1061, 2014.

[3] Kojima, A., Natsu, W., and Kunieda, M., "Spectroscopic Measurement of Arc Plasma Diameter in EDM", CIRP Annals - Manufacturing Technology, Volume 57, No. 1,pp. 203-207, 2008.

[4] Srinivasa, A., Rao, K.R., and Satyanarayana, B., "Effect of Wire EDM Conditions on Generation of Residual Stresses in Machining of Aluminum 2014 T6 Alloy", Alexandria Engineering Journal, Volume 55, No. 6, pp. 1077-1084, 2016.

[5] Sim, W.-G., Song, J.-W., Hong, S.-J., and Kim, K.-S., "Characteristics of Machined Surface Layer of Cemented Carbide by Wire Electrical Discharge Machine", Current Nanoscience, Volume 10, pp. 56-61, 2014.

[6] Saleem, M., and Mufti, N., "Performance Optimization of Electrical Discharge Machining (Die Sinker) for Al6061 via Taguchi Approach”, 2015.

Li, L., Gu, L., Xi, X., and Zhao, W., "Influence of Flushing on Performance of EDM with Bunched Electrode", The International Journal of Advanced Manufacturing Technology, Volume 58, No. 1-4, pp. 187-194, 2012.

[8] Makenzi, M., and Ikua, B., "A Review of Flushing Techniques Used in Electrical Discharge Machining", Proceedings of Sustainable Research and Innovation Conference, pp. 162-165, 2014.

[10] Bamberg, E., and Heamawatanachai, S., "Orbital Electrode Actuation to Improve Efficiency of Drilling Micro-Holes by Micro-EDM", Journal of Materials Processing Technology, Volume 209, No. 4, pp. 1826-1834, 2009.

[11] Garn, R., Schubert, A., and Zeidler, H., "Analysis of the Effect of Vibrations on the Micro-EDM Process at the Workpiece Surface", Precision Engineering, Volume 35, No. 2, pp. 364-368, 2011.
[12] Wang, J., Han, F., Cheng, G., and Zhao, F., "Debris and Bubble Movements during Electrical Discharge Machining", International Journal of Machine Tools and Manufacture, Volume 58, pp. 11-18, 2012.

[13] Singh, S., Maheshwari, S., and Pandey, P.C., "Some Investigations into the Electric Discharge Machining of Hardened Tool Steel Using Different Electrode Materials", Journal of Materials Processing Technology, Volume 149, No. 1-3,pp. 272-277, 2004.

[14] Kunieda, M., Lauwers, B., Rajurkar, K.P., and Schumacher, B.M., "Advancing EDM Through Fundamental Insight into the Process", CIRP Annals Manufacturing Technology, Volume 54, No. 2, pp. 64-87, 2005.

[15] Shabgard, M., Seyedzavvar, M., and Oliaei, S.N.B., "Influence of Input Parameters on the Characteristics of the EDM Process", Strojniški Vestnik - Journal of Mechanical Engineering, Volume 57, No. 9, pp. 689-696, 2011.

[16] Arooj, S., Shah, M., Sadiq, S., Jaffery, S.H.I., and Khushnood, S., "Effect of Current in the EDM Machining of Aluminum 6061 T6 and its Effect on the Surface Morphology", Arabian Journal for Science and Engineering, Volume 39, No. 5, pp. 4187-4199, 2014.

[17] Mehmood, S., Pasha, R.A., and Sultan, A., "Effect of Electric Discharge Machining on Material Removal Rate and White Layer Composition", Mehran University Research Journal of Engineering \& Technology, Jamshoro, Pakistan, 2015.

[18] Chakraborty, S., Dey, V., and Ghosh, S.K., "A Review on the Use of Dielectric Fluids and their Effects in Electrical Discharge Machining Characteristics", Precision Engineering, Volume 40, pp. 1-6, 2015.

[19] Khalaj Amineh, S., Fadaei Tehrani, A., and Mohammadi, A., "Improving the Surface Quality in Wire Electrical Discharge Machined Specimens by Removing the Recast Layer Using Magnetic Abrasive Finishing Method", The International Journal of Advanced Manufacturing Technology, Volume 66, No. 9-12, pp. 1793-1803, 2013.

[20] Ghanem, F., Fredj, N.B., Sidhom, H., and Braham, C., "Effects of Finishing Processes on the Fatigue Life Improvements of Electro-Machined Surfaces of Tool Steel", The International Journal of Advanced Manufacturing Technology, Volume 52, No. 5-8, pp. 583-595, 2010.

[21] Soo, S.L., Antar, M.T., Aspinwall, D.K., Sage, C., Cuttell, M., Perez, R., "The Effect of Wire Electrical Discharge Machining on the Fatigue Life of Ti-6Al-2Sn-4Zr-6Mo Aerospace Alloy", Procedia CIRP, Volume 6, pp. 216-220, 2013. 